\title{
Review
}

\section{The Practicalities of Assessing Freezing of Gait}

\author{
Claudia Barthel $^{\mathrm{a}, 1, *}$, Elizabeth Mallia ${ }^{\mathrm{b}, 1}$, Bettina Debû ${ }^{\mathrm{c}, \mathrm{d}}$, Bastiaan R. Bloem ${ }^{\mathrm{a}}$ \\ and Murielle Ursulla Ferraye ${ }^{\mathrm{a}, \mathrm{e}}$ \\ ${ }^{a}$ Radboud University Medical Centre, Donders Institute for Brain, Cognition and Behaviour, \\ Department of Neurology, Nijmegen, The Netherlands \\ ${ }^{\mathrm{b}}$ Sobell Department for Motor Neuroscience and Movement Disorders, Institute of Neurology, London, UK \\ ${ }^{\mathrm{c}}$ Univ. Grenoble Alpes, Grenoble Institut des Neurosciences, GIN, Grenoble, France \\ ${ }^{\mathrm{d}}$ Inserm, Grenoble, France \\ ${ }^{\mathrm{e}}$ Radboud University, Donders Institute for Brain, Cognition and Behaviour, Nijmegen, The Netherlands
}

Accepted 30 August 2016

\begin{abstract}
.
Background: Freezing of gait (FOG) is a mysterious, complex and debilitating phenomenon in Parkinson's disease. Adequate assessment is a pre-requisite for managing FOG, as well as for assigning participants in FOG research. The episodic nature of FOG, as well as its multiple clinical expressions make its assessment challenging.

Objective: To highlight the available assessment tools and to provide practical, experience-based recommendations for reliable assessment of FOG.

Methods: We reviewed FOG assessment from history taking, questionnaires, lab and home-based measurements and examined how these methods account for presence and severity of FOG, their limits and advantages. The practicalities for their use in clinical and research practice are highlighted.

Results: According to the available assessment tools severity of FOG is marked by one or a combination of multiple clinical expressions including frequency, duration, triggering circumstances, response to levodopa, association with falls and fear of falling, or need for assistance to avoid falls.

Conclusions: To date, a unique methodological tool that encompasses the entire complexity of FOG is lacking. Combining methods should give a better picture of FOG severity, in accordance with the precise clinical or research context. Further development of any future assessment tool requires understanding and thorough analysis of the specific clinical expressions of FOG.
\end{abstract}

Keywords: Parkinson disease, gait disorders, neurologic, disability, evaluation, objective measure

\footnotetext{
${ }^{1}$ Joint first authorship.

*Correspondence to: Claudia Barthel, MSc, Donders Institute for Brain, Cognition and Behaviour, Radboud University Medical Centre, Department of Neurology, P.O. Box 9101, $6500 \mathrm{HB}$ Nijmegen, The Netherlands. Tel.: +31 2436152 05; E-mail: Claudia.Barthel@radboudumc.nl.
}

\section{INTRODUCTION}

Freezing is commonly observed in Parkinson's disease and Parkinsonism and may affect leg, hand and speech movements [1]. Here, we focus on freezing of gait (FOG). FOG is an episodic absence or marked reduction of forward progression of the feet despite the intention to walk [2]. Although this definition is 
very functional, it does not reflect the multiple clinical and physiological expressions of the phenomenon. FOG can be very "troublesome" and is often responsible for falls [3]. Successful assessment of FOG is a pre-requisite for managing the symptom as well as for assigning participants in FOG research [4].

\section{THE CHALLENGE OF ASSESSING FOG}

There are multiple reasons why FOG assessment is challenging. Because it is an episodic phenomenon [4], its observation may require the use of triggering tricks, such as increased cognitive load, as in dual tasking, or stressful situations, such as reacting under time pressure [5]; in addition, FOG may disappear during the examination due to the patient paying extra attention to gait [4]. Indeed, cognitive [6] and affective factors [7] contribute to the episodic nature of FOG. Therefore, FOG assessment should start as soon as the patient stands up from the waiting room chair because it may be the single opportunity to observe it before attentional mechanisms start to suppress it. This episodic nature may hinder the assessment of FOG by objective methods lending weight to the use of subjective assessment tools $[2,8]$. The reliability of such subjective methods hinges on the awareness of FOG among the patients and caregivers. Objective home and lab-based methods are necessary to enquire further about FOG as it varies in its onset in the course of the disease [9]; response to levodopa [9, 10], clinical manifestation [2, 11], triggering circumstances (start hesitation, turn and destination FOG, shuffling forward with short steps) [4], relation to cognitive dysfunction [5], and association with postural instability and falls [12, 13]. Festination is defined as the tendency to move forward with increasingly rapid, but ever smaller steps and is frequently present in patients with FOG. However, because it does not systematically precede FOG, as in start hesitation, we consider it as a separate, gait disturbance [2]. A decision tree can help to pin down freezer/non-freezer classification by identifying 3 categories: (1) "self-reported freezer", when freezing is only attested by self-report; (2) "probable freezer", when presence of FOG is confirmed by a third person (caregiver); and (3) "definite freezer", when freezing is actually observed during formal objective testing by an experienced professional [14]. Further evaluation using home or lab-based quantitative testing has been suggested to confirm the presence of FOG in self-reported and probable freezers.
In practice, the FOG assessment(s) chosen depends on the context, with subjective methods used mostly in routine clinical setting, and objective methods, especially needed in research settings or when treatment adjustment is needed. However, a combination of both may provide a fuller picture. Here we review the assessment tools for FOG, distinguishing between subjective, clinical and objective tools. We highlight their advantages and limitations within clinical and research settings and offer an experience-based account. We place special emphasis on each assessment tool's ability to mark FOG severity as the severity of FOG impacts changes in medication or Deep Brain Stimulation (DBS) settings, as well as therapy (for example physiotherapy, occupational therapy).

\section{SUBJECTIVE METHODS}

\section{History-taking}

This interview allows for the clarification of the meaning of FOG with the patient, and is the start of the inquiry into how troublesome FOG is for the purpose of managing the symptom [3]. Rather than referring to 'freezing' a patient can be asked about the typical experience of feeling as if their feet were glued to the floor, or about being suddenly unable to move forward [3]. It is also helpful to demonstrate what freezing actually looks like, both to the patient and caregiver by e.g. showing patients a video of examples of variants of FOG, as is done in the New Freezing of Gait Questionnaire (NFOGQ) [15]. Videos describing FOG from a patient's point of view can make it less daunting for a patient to identify their symptoms [16].

Incorporating the NFOGQ at this point is useful to probe the severity of FOG. Asking about the effect of medication is necessary to separate out levodopa-responsive vs. levodopa-resistant FOG. In addition, as FOG constitutes a major risk factor for falls in Parkinson patients, it is recommended to ask for past falls or about the fear of falling.

\section{Questionnaire-based assessment methods}

Questionnaires provide a global overview of FOG that complements other measures in the clinic, and for research purposes such as when a follow-up by phone is required. 
The unified Parkinson's disease rating scale [17] or the Movement Disorder Society-UPDRS (UPDRS Part II, item 14, and MDS-UPDRS Part II, item 2.13: Activities of Daily Living) [18] offers the opportunity to ask the patient about the presence and severity of FOG both OFF and ON medication. This is needed if it is not possible for the examiner to perform a levodopa challenge. Knowing if the patient has dopamine-responsive, dopamineresistant or dopamine-induced FOG is critical for further management [3]. Compared with the former UPDRS, the MDS-UPDRS measures fall risk instead of actual falls. The UPDRS questionnaires only allow the examiner to get some insight into the presence and burden of FOG in daily life, and not to finely characterize its features.

Apart from the FOG items from the MDS-UPDRS, two validated questionnaires exist: the original Freezing of Gait Questionnaire (FOGQ) [19] and the NFOGQ [15]. The NFOGQ is very useful as it measures the severity of FOG in terms of frequency of occurrence, intensity and duration of the longest FOG episodes, and subjective impact on quality of life and activities of daily living. However, the questions only stress gait initiation and turning, which are the most common triggers of FOG [10], but not the only ones, and no distinction is made between FOG in the ON and/or OFF states. The Gait and falls questionnaire (GFQ) includes questions relating to gait in general and falls, and is therefore not deemed specific enough for FOG assessment [20]. However, compared to the NFOGQ, it covers a larger range of FOG triggering circumstances and questions patients both about the longest and a typical FOG episode, which might be more sensitive to detect changes associated with therapeutic adjustments. On their own questionnaires seldom suffice; even more so as the questionnaire outcome and objective measures might not necessarily correlate [21].

\section{Home-based assessment methods}

Given that FOG is most commonly experienced at home [22], assessing FOG in a person's home environment carries a lot of merit. It provides ecological information on FOG occurrence in daily life. In addition, it enables the recording of fluctuations of FOG during the day, a feature that cannot be grasped during a patient's visit or during laboratory measurement.

Diaries, paper or online ones, are a cost-effective way to assess FOG that can yield information on the burden of the symptom in the patient's daily life
[3]. Once FOG behavior to be recorded has been described to the patient and caregiver [23], a carefully structured diary may gather the frequency of FOG episodes, time of day, triggering circumstances (such as walking through a doorway), and whether the episode resulted in a fall or a near-fall. This information can allow pharmacological treatment and Deep Brain Stimulation settings to be adjusted [24], help define specific physiotherapy and occupational therapy goals, and inform on the efficacy of an intervention. Asking the patient to keep a diary would enable the adjustment of DBS settings and provide information on the time course of the effect. The drawback of a diary is that reports lie in the hands of patients even more than for questionnaires. The diary can only be kept by patients without cognitive issues, and, depending on the purpose and duration over which it needs to be filled, it requires followup by a researcher or therapist every week to ensure correct completion [25, 26]. Even then, it can prove impossible to record all FOG episodes, especially in patients with severe FOG. Given these limitations diaries should be combined with other assessment methods. In this way they can yield useful information on the burden of the symptom in the patient's daily life [3].

\section{CLINICAL EXAMINATION}

Clinical examination aims at objectively verifying the presence of FOG and assessing severity, responsiveness to treatment, and triggering circumstances, in an environment where time is precious.

The MDS-UPDRS III FOG item allows for the clinical recording of the severity of the symptom based on its precipitating circumstances [18]. It assesses the severity of FOG on a 0 to 4 scale, with FOG during straight walking considered to be more severe than FOG occurring during turning, starting or walking in a narrow space. However, as FOG is assessed through a single item that may miss out possible FOG triggering circumstances it is not sensitive enough. In addition, it does not take the duration of the episodes into account.

Ziegler et al. proposed a clinical rating instrument for FOG and festination [27], termed the FOG score. This FOG score measures the occurrence of FOG in a trajectory comprising four possible triggering circumstances (start hesitation, clockwise and counter clockwise turns, narrow space), combined or not with a dual task. Its originality comes from 
the discrimination between the different FOG clinical patterns, with festination or shuffling considered less severe than FOG associated with leg trembling or akinetic FOG, which in turn is less severe than FOG causing abortion of task or need for external help and/or cue. This FOG score is a cost-effective instrument for detailed examination of FOG but takes up to 15 minutes to administer. Also, it does not incorporate all possible FOG triggers in the computation of FOG severity, especially when these could further inform on FOG severity, with FOG occurring while walking straight being the most severe form. Weighting the different triggering circumstances by recording their frequency [28] would augment the instrument's utility. Finally, the FOG score does not consider the duration of FOG episodes even though, beyond the simple occurrence of FOG itself, FOG duration is a major indicator of FOG severity.

Because of the lack of a satisfyingly comprehensive clinical scoring tool, a number of authors have used so-called "FOG trajectories" to objectify FOG during clinical examination $[4,10,14,24,29$, 30]. Examination of freezing typically includes 360 degree rapid turns, small steps walking, stops on command, narrow or cluttered passages, dual motortasking such as carrying a tray, and cognitive dual tasking. Caution should however be exercised as such maneuvers may lead to falls. It is recommended to stand close to the patients, especially when asking them to perform the rapid short steps test, as they tend to walk very fast and fall over. Using a safety harness, usually available in a lab, during rapid, full turns can allow FOG to be detected with less turns, as the person being tested is more likely to turn more rapidly, than they would if the test were being conducted in a normal examination room. Stepping in place and backward walking may also trigger FOG in some patients [31, 32]. Such clinical assessment can be adapted to each patient individually. If the aim is simply to detect FOG, then assessment can stop as soon as the symptom is observed. Conversely, in a patient with self-reported FOG who does not immediately demonstrate FOG during clinical examination, it is useful to combine several triggering circumstances. Increasing the cognitive load will prevent patients from relying on attentional processes to control gait, and this may help to unveil FOG.

Sometimes, even such complex and distracting tasks will not trigger FOG during the clinical evaluation in a known freezer. In such cases, assessment should be repeated at another visit, and possibly in a practically defined OFF state (to minimize a masking effect by dopaminergic medication).

\section{OBJECTIVE METHODS}

\section{Lab-based assessment methods}

For research into specific effects on FOG a lab assessment is necessary. In the lab, a clinical test battery can be supplemented with gait protocols. The FOG event(s) can be captured on video [24, 33] for off-line, blinded, experienced rating which is the current gold standard for assessing the severity of FOG [34]. Video recording may be synchronized with assessment technology, including motion capture systems, inertial sensors [35] or pressure sensitive insoles and mats to capture very short FOG episodes which may be missed by the naked clinical eye [36], as well as abnormal gait parameters just prior or in between an episode.

An advantage of assessing FOG in a lab environment is the ability to assess and compare a patient in both a well-defined ON (using a supramaximal levodopa dose), and OFF state (overnight withdrawal of dopaminergic medication) [37]. In the case of OFF state freezers (which is the most common subtype), especially during the early stages of PD $[2,10]$, FOG can be difficult to elicit in a standard clinical setting as patients usually take their medication before the visit [4]. Being able to test a patient in the OFF state both increases the likelihood of detecting FOG and enables one to document the effect of medication, as well as its time course during the levodopa challenge. However, lab testing remains limited in informing on FOG severity as it is too short an assessment to capture FOG longitudinally. For this reason it is important to supplement lab data with a questionnaire such as the NFOGQ or a home-based assessment.

\section{Home-based assessment methods}

Wearable technology containing inertial sensors holds promise for a more objective assessment of FOG. The recording of gait abnormalities in between or prior to FOG episodes [38] provide a fuller picture of the FOG events allowing more accurate assessment of therapeutic strategies [39]. To our knowledge this wearable technology is still only used in research settings and clinical application will depend on further development of automated feature learning for the detection of FOG episodes. This challenge arises 
Table 1

Markers of severity of FOG: existing assessment tools, uses and main drawbacks

\begin{tabular}{|c|c|c|c|c|}
\hline & Tool/method & Markers of FOG severity & Use & Main drawback \\
\hline \multirow[t]{6}{*}{ Subjective } & UPDRS II, item 14 & $\begin{array}{l}\text { Falls frequency } \\
\text { Response to medication }\end{array}$ & $\begin{array}{l}\text { Neurological examination } \\
\text { Lab-based research study }\end{array}$ & $\begin{array}{l}\text { Relies on patient ability to } \\
\text { report on FOG }\end{array}$ \\
\hline & MDS-UPDRS II, item 2.13 & Need for assistance & & \\
\hline & History taking & $\begin{array}{l}\text { FOG presence/absence } \\
\text { How troublesome FOG is } \\
\text { Response to medication }\end{array}$ & & \\
\hline & NFOGQ & $\begin{array}{l}\text { FOG frequency } \\
\text { FOG duration } \\
\text { Need for assistance } \\
\text { Fear of falling } \\
\text { FOG impact on daily living }\end{array}$ & & \\
\hline & FOGQ & $\begin{array}{l}\text { FOG duration } \\
\text { Need for assistance } \\
\text { FOG impact on daily living } \\
\quad \text { (very brief) }\end{array}$ & & \\
\hline & Diaries & $\begin{array}{l}\text { FOG frequency } \\
\text { FOG duration } \\
\text { FOG triggering } \\
\text { circumstances } \\
\text { Time of day FOG occurs } \\
\text { Occurrence relative to } \\
\text { medication } \\
\text { Number of FOG-related falls }\end{array}$ & $\begin{array}{l}\text { Home based intervention } \\
\text { study } \\
\text { Follow-up of patient }\end{array}$ & Relies on patient compliance \\
\hline \multirow[t]{4}{*}{ Objective } & MDS-UPDRS III, item 3.11 & $\begin{array}{l}\text { FOG presence } \\
\text { FOG frequency } \\
\text { FOG triggering } \\
\text { circumstances }\end{array}$ & $\begin{array}{l}\text { Neurological examination } \\
\text { Lab-based research study }\end{array}$ & $\begin{array}{l}\text { Captures only a "moment in } \\
\text { time" }\end{array}$ \\
\hline & Lab-measurement/video & $\begin{array}{l}\text { FOG frequency } \\
\text { FOG duration } \\
\text { FOG triggering } \\
\quad \text { circumstances } \\
\text { Number of near-falls/falls } \\
\text { Response to medication } \\
\text { Gait parameters }\end{array}$ & & \\
\hline & FOG score & $\begin{array}{l}\text { FOG presence } \\
\text { FOG triggering } \\
\text { circumstances }\end{array}$ & & \\
\hline & Sensors & $\begin{array}{l}\text { FOG frequency } \\
\text { FOG duration } \\
\text { Time of day FOG occurs } \\
\text { Gait parameters }\end{array}$ & $\begin{array}{l}\text { Home based intervention } \\
\text { study } \\
\text { Lab-based research study } \\
\text { (except for 'Time of day } \\
\text { FOG occurs') } \\
\text { Follow-up of patient }\end{array}$ & $\begin{array}{l}\text { Requires further development } \\
\text { to reliably pick up all FOG } \\
\text { clinical patterns }\end{array}$ \\
\hline
\end{tabular}

UPDRS, Unified Parkinson's disease rating scale [17]; MDS-UPDRS, Movement Disorder Society-UPDRS [18]; NFOGQ, New Freezing of Gait Questionnaire [15]; FOGQ, Freezing of Gait Questionnaire [19]; FOG score, Freezing of Gait-Score [27].

because of the different clinical patterns of FOG [11]. The most common form involves leg trembling with no effective forward motion (the trembling-inplace pattern). FOG detection algorithms capturing this $3-8 \mathrm{~Hz}$ oscillation pattern of the legs [40] yield the best results when the inertial sensor is placed on the shank, above the ankle joint [41, 42], especially, from our experience, on the leg that is hesitant dur- ing movement initiation. The sensitivity for an IMU placed at the shank is high though the specificity is rather low [41]. Additionally there is good correlation for the number of episodes (ICC 0.78) and very strong correlation for percent time frozen (ICC 0.93 ) between the accelerometry derived method for detecting $3-8 \mathrm{~Hz}$ oscillation pattern of the legs and the clinical offline video rating [43]. Alternatively 
a triaxial accelerometer worn at the waist when employing a linear support vector machine analysis approach can yield very high accuracy $(98.7 \%)$ in detecting FOG [44]. However, the accuracy may decrease when the method is used in an unconstrained home environment. Furthermore, this state-of-the-art method has only been tested on very small population samples.

In some patients, FOG is associated with festination [45] in which short, shuffling steps are observed but forward movement is minimal. Recently, an algorithm evaluating cadence and stride length data from an IMU placed on the shank has been developed to detect this 'festinating' type of FOG [39]. FOG can also manifest as complete akinesia, where no motion of the legs is observed and patients describe an interim period where they passively wait for the spontaneous resolution of the FOG episode. This last clinical pattern of FOG is a challenge for detection algorithms as it can be confused with simple stance [46]. A more in depth review of available algorithms to detect FOG has recently been published [47].

Home-based assessments are not an option when the effect of adjunct/germinal therapies for FOG last a short while. Such is the case for repetitive transcranial magnetic stimulation (rTMS) [48], where the assessment of FOG should be done at most within one hour following the stimulation protocol [49]. Particularly in such cases, lab-based assessments are necessary.

\section{TAKE HOME MESSAGE}

Careful assessment of FOG is a pre-requisite for fine-tuning the management strategy. From a researcher's point of view, properly stratifying into freezers and non-freezers but also into different FOG subtypes appears important for further understanding of the phenomenon. To date, a unique methodological tool that encompasses the entire complexity of FOG is lacking and the best marker of severity is unclear: patient's self-evaluation of FOG severity, clinical pattern, triggering circumstances, FOG frequency, FOG duration, response to levodopa or need for assistance to avoid falls (Table 1). Further development of such an assessment tool requires understanding and thorough analysis of the specific FOG characteristics. As it stands, to reliably assess FOG severity, a combination of FOG assessment tools is necessary, in accordance with the clinical or specific research context of the assessment need.

\section{ACKNOWLEDGMENTS}

This research was funded by a European Community's Seventh Framework Programme FP7/2012 to C Barthel and E Mallia under grant agreement No. 316639.

\section{CONFLICT OF INTEREST}

The authors have no conflict of interest to report.

\section{REFERENCES}

[1] Vercruysse S, Gilat M, Shine JM, Heremans E, Lewis S, \& Nieuwboer A (2014) Freezing beyond gait in Parkinson's disease: A review of current neurobehavioral evidence. $\mathrm{Neu}$ rosci Biobehav Rev, 43, 213-227.

[2] Nutt JG, Bloem BR, Giladi N, Hallett M, Horak FB, \& Nieuwboer A (2011) Freezing of gait: Moving forward on a mysterious clinical phenomenon. Lancet Neurol, 10, 734744.

[3] Nonnekes J, Snijders AH, Nutt JG, Deuschl G, Giladi N, \& Bloem BR (2015) Freezing of gait: A practical approach to management. Lancet Neurol, 14, 768-778.

[4] Snijders AH, Nijkrake MJ, Bakker M, Munneke M, Wind C, \& Bloem BR (2008) Clinimetrics of freezing of gait. Mov Disord, 23(Suppl 2), S468-S474.

[5] Heremans E, Nieuwboer A, Spildooren J, Vandenbossche J, Deroost N, Soetens E, Kerckhofs E, \& Vercruysse S (2013) Cognitive aspects of freezing of gait in Parkinson's disease: A challenge for rehabilitation. J Neural Transm, 120, 543557.

[6] Nieuwboer A, \& Giladi N (2013) Characterizing freezing of gait in Parkinson's disease: Models of an episodic phenomenon. Mov Disord, 28, 1509-1519.

[7] Ehgoetz Martens KA, Ellard CG, \& Almeida QJ (2014) Does anxiety cause freezing of gait in Parkinson's disease? PLoS One, 9, e106561.

[8] Heremans E, Nieuwboer A, \& Vercruysse S (2013) Freezing of gait in Parkinson's disease: Where are we now? Curr Neurol Neurosci Rep, 13, 350.

[9] Giladi N, McDermott MP, Fahn S, Przedborski S, Jankovic J, Stern M, Tanner C, \& Parkinson Study G (2001) Freezing of gait in PD: Prospective assessment in the DATATOP cohort. Neurology, 56, 1712-1721.

[10] Schaafsma JD, Balash Y, Gurevich T, Bartels AL, Hausdorff JM, \& Giladi N (2003) Characterization of freezing of gait subtypes and the response of each to levodopa in Parkinson's disease. Eur J Neurol, 10, 391-398.

[11] Thompson PD, \& Marsden CD (1995) Walking disorder. In Neurology in Clinical Practice - Principles of Diagnosis and Management, Bradley WG, Daroff RB, Fenichel GM, Marsden CD, eds. Butterworth-Heinemann, Boston, pp. 321-334.

[12] Bloem BR, Hausdorff JM, Visser JE, \& Giladi N (2004) Falls and freezing of gait in Parkinson's disease: A review of two interconnected, episodic phenomena. Mov Disord, 19, 871-884.

[13] Nantel J, \& Bronte-Stewart H (2014) The effect of medication and the role of postural instability in different 
components of freezing of gait (FOG). Parkinsonism Relat Disord, 20, 447-451.

[14] Snijders AH, Haaxma CA, Hagen YJ, Munneke M, \& Bloem BR (2012) Freezer or non-freezer: Clinical assessment of freezing of gait. Parkinsonism Relat Disord, 18, 149-154.

[15] Nieuwboer A, Rochester L, Herman T, Vandenberghe W, Emil GE, Thomaes T, \& Giladi N (2009) Reliability of the new freezing of gait questionnaire: Agreement between patients with Parkinson's disease and their carers. Gait Posture, 30, 459-463.

[16] Stummer C, \& Bloem B (2015) ParkinsonNet, https:// www.youtube.com/watch?v=szyVFO5110E, Posted June 1, 2015, Accessed July 20, 2016.

[17] Fahn S, Marsden CD, Goldstein M, \& Calne DB (1987) Unified Parkinsons Disease Rating Scale, Macmillan Healthcare Information.

[18] Goetz CG, Tilley BC, Shaftman SR, Stebbins GT, Fahn S, Martinez-Martin P, Poewe W, Sampaio C, Stern MB, Dodel R, Dubois B, Holloway R, Jankovic J, Kulisevsky J, Lang AE, Lees A, Leurgans S, LeWitt PA, Nyenhuis D, Olanow CW, Rascol O, Schrag A, Teresi JA, van Hilten JJ, LaPelle N, \& Movement Disorder Society URTF (2008) Movement Disorder Society-sponsored revision of the Unified Parkinson's Disease Rating Scale (MDS-UPDRS): Scale presentation and clinimetric testing results. Mov Disord, 23, 2129-2170.

[19] Giladi N, Tal J, Azulay T, Rascol O, Brooks DJ, Melamed E, Oertel W, Poewe WH, Stocchi F, \& Tolosa E (2009) Validation of the freezing of gait questionnaire in patients with Parkinson's disease. Mov Disord, 24, 655-661.

[20] Giladi N, Shabtai H, Simon ES, Biran S, Tal J, \& Korczyn AD (2000) Construction of freezing of gait questionnaire for patients with Parkinsonism. Parkinsonism Relat Disord, 6, $165-170$.

[21] Shine JM, Moore ST, Bolitho SJ, Morris TR, Dilda V, Naismith SL, \& Lewis SJG (2012) Assessing the utility of Freezing of Gait Questionnaires in Parkinson's Disease. Parkinsonism Relat Disord, 18, 25-29.

[22] Nieuwboer A, \& Giladi N (2008) The challenge of evaluating freezing of gait in patients with Parkinson's disease. $\mathrm{Br}$ J Neurosurg, 22(Suppl 1), S16-S18.

[23] Montgomery GK, \& Reynolds NC Jr (1990) Compliance, reliability, and validity of self-monitoring for physical disturbances of Parkinson's disease. The Parkinson's Symptom Diary. J Nerv Ment Dis, 178, 636-641.

[24] Ferraye MU, Debu B, Fraix V, Goetz L, Ardouin C, Yelnik J, Henry-Lagrange C, Seigneuret E, Piallat B, Krack P, Le Bas JF, Benabid AL, Chabardes S, \& Pollak P (2010) Effects of pedunculopontine nucleus area stimulation on gait disorders in Parkinson's disease. Brain, 133, 205-214.

[25] Giladi N, \& Nieuwboer A (2008) Understanding and treating freezing of gait in parkinsonism, proposed working definition, and setting the stage. Mov Disord, 23(Suppl 2), S423-S425.

[26] Pelosin E, Avanzino L, Bove M, Stramesi P, Nieuwboer A, \& Abbruzzese G (2010) Action observation improves freezing of gait in patients with Parkinson's disease. Neurorehabil Neural Repair, 24, 746-752.

[27] Ziegler K, Schroeteler F, Ceballos-Baumann AO, \& Fietzek UM (2010) A new rating instrument to assess festination and freezing gait in Parkinsonian patients. Mov Disord, 25, 1012-1018.

[28] Rahman S, Griffin HJ, Quinn NP, \& Jahanshahi M (2008) The factors that induce or overcome freezing of gait in Parkinson's disease. Behav Neurol, 19, 127-136.
[29] Moreau C, Delval A, Defebvre L, Dujardin K, Duhamel A, Petyt G, Vuillaume I, Corvol JC, Brefel-Courbon C, Ory-Magne F, Guehl D, Eusebio A, Fraix V, Saulnier PJ, Lagha-Boukbiza O, Durif F, Faighel M, Giordana C, Drapier S, Maltete D, Tranchant C, Houeto JL, Debu B, Sablonniere B, Azulay JP, Tison F, Rascol O, Vidailhet M, Destee A, Bloem BR, Bordet R, Devos D, \& Parkgait IIsg (2012) Methylphenidate for gait hypokinesia and freezing in patients with Parkinson's disease undergoing subthalamic stimulation: A multicentre, parallel, randomised, placebocontrolled trial. Lancet Neurol, 11, 589-596.

[30] Nonnekes J, Janssen AM, Mensink SH, Oude Nijhuis LB, Bloem BR, \& Snijders AH (2014) Short rapid steps to provoke freezing of gait in Parkinson's disease. J Neurol, 261, 1763-1767.

[31] Nantel J, de Solages C, \& Bronte-Stewart H (2011) Repetitive stepping in place identifies and measures freezing episodes in subjects with Parkinson's disease. Gait Posture, 34, 329-333.

[32] Peterson DS, Plotnik M, Hausdorff JM, \& Earhart GM (2012) Evidence for a relationship between bilateral coordination during complex gait tasks and freezing of gait in Parkinson's disease. Parkinsonism Relat Disord, 18, 10221026.

[33] Nieuwboer A, Dom R, De Weerdt W, Desloovere K, Janssens L, \& Stijn V (2004) Electromyographic profiles of gait prior to onset of freezing episodes in patients with Parkinson's disease. Brain, 127, 1650-1660.

[34] Morris TR, Cho C, Dilda V, Shine JM, Naismith SL, Lewis SJG, \& Moore ST (2013) Clinical assessment of freezing of gait in Parkinson's disease from computer-generated animation. Gait Posture, 38, 326-329.

[35] Tanahashi T, Yamamoto T, Endo T, Fujimura H, Yokoe M, Mochizuki H, Nomura T, \& Sakoda S (2013) Noisy interlimb coordination can be a main cause of freezing of gait in patients with little to no parkinsonism. PLoS One, $\mathbf{8}, \mathrm{e} 84423$.

[36] Zach H, Janssen AM, Snijders AH, Delval A, Ferraye MU, Auff E, Weerdesteyn V, Bloem BR, \& Nonnekes J (2015) Identifying freezing of gait in Parkinson's disease during freezing provoking tasks using waist-mounted accelerometry. Parkinsonism Relat Disord, 21, 1362-1366.

[37] Langston JW, Widner H, Goetz CG, Brooks D, Fahn S, Freeman T, \& Watts R (1992) Core assessment program for intracerebral transplantations (CAPIT). Mov Disord, 7, 2-13.

[38] Weiss A, Herman T, Giladi N, \& Hausdorff JM (2015) New evidence for gait abnormalities among Parkinson's disease patients who suffer from freezing of gait: Insights using a body-fixed sensor worn for 3 days. J Neural Transm (Vienna), 122, 403-410.

[39] Coste CA, Sijobert B, Pissard-Gibollet R, Pasquier M, Espiau B, \& Geny C (2014) Detection of freezing of gait in Parkinson disease: Preliminary results. Sensors (Basel), 14, 6819-6827.

[40] Moore ST, MacDougall HG, \& Ondo WG (2008) Ambulatory monitoring of freezing of gait in Parkinson's disease. $J$ Neurosci Methods, 167, 340-348.

[41] Moore ST, Yungher DA, Morris TR, Dilda V, MacDougall HG, Shine JM, Naismith SL, \& Lewis SJ (2013) Autonomous identification of freezing of gait in Parkinson's disease from lower-body segmental accelerometry. $J$ Neuroeng Rehabil, 10, 19.

[42] Yungher DA, Morris TR, Dilda V, Shine JM, Naismith SL, Lewis SJ, \& Moore ST (2014) Temporal characteristics of high-frequency lower-limb oscillation during freezing of gait in Parkinson's disease. Parkinsons Dis, 2014, 606427. 
[43] Morris TR, Cho C, Dilda V, Shine JM, Naismith SL, Lewis SJ, \& Moore ST (2012) A comparison of clinical and objective measures of freezing of gait in Parkinson's disease. Parkinsonism Relat Disord, 18, 572-577.

[44] Ahlrichs C, Sama A, Lawo M, Cabestany J, RodriguezMartin D, Perez-Lopez C, Sweeney D, Quinlan LR, Laighin GO, Counihan T, Browne P, Hadas L, Vainstein G, Costa A, Annicchiarico R, Alcaine S, Mestre B, Quispe P, Bayes A, \& Rodriguez-Molinero A (2016) Detecting freezing of gait with a tri-axial accelerometer in Parkinson's disease patients. Med Biol Eng Comput, 54, 223-233.

[45] Iansek R, Huxham F, \& McGinley J (2006) The sequence effect and gait festination in Parkinson disease: Contributors to freezing of gait? Mov Disord, 21, 1419-1424.

[46] Djuric-Jovicic MD, Jovicic NS, Radovanovic SM, Stankovic ID, Popovic MB, \& Kostic VS (2014) Automatic identification and classification of freezing of gait episodes in Parkinson's disease patients. IEEE Trans Neural Syst Rehabil Eng, 22, 685-694.

[47] Delval A, Tard C, Rambour M, Defebvre L, \& Moreau C (2015) Characterization and quantification of freezing of gait in Parkinson's disease: Can detection algorithms replace clinical expert opinion? Neurophysiol Clin, 45, 305313.

[48] Lee SY, Kim MS, Chang WH, Cho JW, Youn JY, \& Kim YH (2014) Effects of repetitive transcranial magnetic stimulation on freezing of gait in patients with Parkinsonism. Restor Neurol Neurosci, 32, 743-753.

[49] Hubl D, Nyffeler T, Wurtz P, Chaves S, Pflugshaupt T, Luthi M, von Wartburg R, Wiest R, Dierks T, Strik WK, Hess CW, \& Muri RM (2008) Time course of blood oxygenation level-dependent signal response after theta burst transcranial magnetic stimulation of the frontal eye field. Neuroscience, 151, 921-928. 